\title{
The Study of Social Intelligence of Students Majoring in "Industrial and civil construction"
}

\author{
Olga Iatsevich $^{1, *}$, Tatiana Semenovskikh ${ }^{2}$ and Zhanna Bruk $^{2}$ \\ ${ }^{1}$ Tyumen Industrial University, Volodarskogo str., 38, Tyumen, 625003, Russia \\ ${ }^{2}$ Tyumen State University, Volodarskogo str., 6, Tyumen, 625003, Russia
}

\begin{abstract}
The article tackles the question of the interconnection between the components of social intelligence (the N. Hall test and the D. V. Lyusin questionnaire test Emln) and self-presentation tactics (the S. Lee, B. Quigley scale). To win on the market of vacancies the graduates have to know how to present themselves and their own projects, and have high social intelligence. The survey of 147 Russian students of Tyumen Industrial university has shown that the subjects with high and low levels of emotional awareness tend to resort to intimidation and managing behavior and emotions as well as such assertive self-presentation tactics as entitlement and blasting. Students with a developed ability to manage their emotions more often than the others declare their virtues and past achievements. Examinees with low and with high ability to control their emotional states can be characterized by negative and critical evaluation of others. The authors emphasize the research prospects of individual human resources where social intelligence as one of the components of the behavioral control is seen as a predictor of various self-presentation tactics, protective and assertive in particular.
\end{abstract}

\section{Introduction}

The society currently places an increasing demand for the educational domain, the quality of bachelor's programs and the level of competencies underlying professional development. There has been an increased demand for qualified graduates in the field of civil engineering capable of solving challenging problems through such personal and professional qualities as social intelligence (SI) and self-presentation their design development.

In today's world all students in addition to their professional learning must also have cultural competence. The process of development of universal competencies stimulates creativity, promotes cultural growth and social mobility of students. The situation of increased competition and uncertainty in the labour market of graduates poses new challenges to the University education. In our opinion, to win on the market of vacancies can only the graduates who knows how to present themselves and their own projects, and have high social intelligence. The aim of our study was to compare the indicators of SI and

\footnotetext{
*Corresponding author: bruk_882@mail.ru
} 
the tactics of self-presentation of all students from course to course as well as the description and analysis of the results.

\section{Theoretical fundamentals of the study of social intelligence}

The recent study of M. Gutierrez-Moret and R. Ibanez-Martinez (2016) highlights the importance of students' EI assessment. Furthermore, Zhou Jiang's study (2016) showed that SI could influence career decision-making self-efficacy (CDMSE) through goal commitment (GC) and professional commitment, and male students exhibited a stronger relationship between SI and GC compared with female students. As demonstrated in H.S. Afshar and M. Rahimi's study (2016), there is a significant positive association among: reflective thinking, social intelligence, and speaking ability. Additionally, the results of multiple regression analyses indicated that both reflective thinking and social intelligence significantly predicted speaking ability with the latter being a stronger predictor. social intelligence plays a crucial role in distressed emotionally difficult decision-making tasks, as revealed by A. Alkozei, S. J. Zachary, W. D.S. Killgore (2016). They hypothesized that higher Emotional intelligence (EI), as one of the part of SI would correlate with greater utilization of socially relevant facial cues during emotional decision-making. Findings suggest that individuals with higher ability EI were more likely to utilize the available but limited social information (i.e., facial features) when completing an emotional decisionmaking task than those with lower EI. In addition, contemporary analyses of learning experience prove the importance of SI formation and development through actualization of students' creative potential in educational environment especially in project activity and self-presentation.

In a number of theories originated in Russia and elsewhere, the ability of a person to understand and to predict the behavior of other people in different situations is believed to be a special knowledge, which forms the basis for categorizing social intelligence as a new approach to the evaluation of the successes of an individual. This concept can be found in: J.P. Guilford, J. Caruso, John. Mayer, P. Salovey. They are the first to introduce social and emotional intelligence as a group of mental abilities, promoting awareness and recognition of their own and other's emotions and behavior. Professional success of the individual is associated with the level of general intelligence. According to H. Gardner (1983), however, individuals with a high level of general intelligence, are not at times competitive and experiencing a number of career difficulties. Perhaps this is due to their inability to distinguish and name feelings easily, and to translate them into symbolic codes useful for behavior management. Emotional intelligence is better understood as a further development of social intelligence (J. Guilford, G. Allport, A. Savenkov et al). The reason for such changes was the discrepancy between the level of general intelligence and a person's ability to interact with his or her social environment (R. Bar-On, 2006, D. Goleman, 2010). The Psycho-pedagogical community in this country consider EI as one of the components of SI, which is:

1. the ability to understand human attitudes represented by emotions, and to manage emotions through intellectual analysis and synthesis (G. Gorskova, 1999, p.p. 25-26);

2. a person's ability to understand and manage their own and others' emotions (I. Andreeva, 2008, p. 39-43, D. Lyusin, 2004, p.p. 129-140);

3. a person's subjective characteristic containing the following: regulation of both internal and external human mental activity; the ability of emotional understanding, cognition of their states and the states of other participants of the communication process; management of their actions toward a conscious goal; regulation of the internal state (needs and desires) connected with the experience of the events and situations influencing their participants (M. Manoilov, 2007, p.p. 126-137). EI is based on the 
ability to discern various emotions, be the intellect or otherwise. The final product of emotional intelligence is a decision-making process based on the reflection and discernment of emotions as differentiated evaluations of events that have acquired personal meaning. Emotional intelligence produces non-obvious ways for achievement of the individual's goals and needs. In contrast to abstract and concrete types of intelligence that reflect the laws of the outside world, emotional intelligence reflects the inner world in its relation to human behavior and interaction with reality. Emotional intelligence in its broadest sense combines a person's ability to communicate effectively by understanding their own emotions and the emotions of others as well as the ability to adjust to their emotional state and to control their emotional manifestations. Such ability of self-control and well-organized interaction is indispensable when it comes to the scope of work, which implies direct contact with others, which is the key to the work in Civil Engineering. Equally important is the ability of self-presentation in various situations, which is determined by the choice of the individual communication style and unique image.

\subsection{The Purpose of the Research}

General intelligence is a factor of academic achievements, where as developed social and its part Emotional intelligence and self-presentation contribute to the success in life and profession. This research deals with modern educational paradigms, wherein a series of general and specific competencies are translated into particular requirements a professional, after all the graduates of "Industrial and civil construction" must not only be able to socially interact with others but also "promote" their exclusive project on the market. However, it does not include the students' SI formation and self-presentation abilities necessary for future competitive professionals.

The research includes three objectives:

- to review theoretical and empirical studies in this area;

- to diagnose the structural components of social, emotional intelligence, as well as the students' self-presentation tactics;

- to carry out a comparative analysis of empirical data and draw conclusions.

\subsection{Participants}

The Tyumen Industrial University, (Tyumen, Russia) provides the evidence base of the research. The study involves 147 students aged from 17 to 22 (I-IV years of education) majoring in "Industrial and civil construction".

\subsection{The Concept of Social Intelligence and its Structure}

The key aspect of the theoretical part of the study was to consider the concept of social intelligence and to determine its structure. The structure of the SI is based on the idea that emotions have information about a person's associations with other people or objects. Changes in these associations entail, in turn, changes in behavior and emotions including the way they are controlled and regulated (superstructure). The ability to produce emotional states leading to success is one of the aspects of regulating emotions.

The analysis of various points of view on the subject of the study allows us to define social intelligence as a combination of cognitive and non-cognitive skills, given the personal characteristics of the individual. Based on this view we can determine the following structural components: perceiving and understanding behavioral aspects and emotions, managing them and using emotions in thinking and other cognitive activities. 
These components of social intelligence influence the optimization of professional training of future specialists in modern university, whereby they involve the formation of students' professional core competencies enabling them to be competitive in their professional activities.

\subsection{Self-Presentation Tactics}

The analysis of the structural components of social intelligence stirred our interest in the way they influence the choice of students' self-presentation tactics. Self-presentation consists of three components: the subject of self-presentation; the subject for selfpresentation; the object of self-presentation. These components are combined by a desirable goal of the subject of self- presentation. The second participant of the interaction is often perceived as an object of influence. Another factor is the environment, which sets the communication rules. One of the key objectives of the study is to identify self-presentation tactics, which are defined as a set of individual's behavioral acts distributed in time and space, aimed at creating a certain image in the eyes of others. The strategy of selfpresentation is a set of different tactics. Under the tactics of self-presentation, we imply the technique of constructing the desired image. One of the first classifications of selfpresentation tactics was developed by E. Jones and T. Pittman (1982). They identify five major tactics: self-promotion (demonstration of competence); intimidation (demonstration of force); ingratiation (the goal is to appear agreeable); exemplification (the goal is to appear morally impeccable); supplication (demonstration of weaknesses in order to receive assistance from others).

We have opted for the classification proposed by S. Lee, B. Quigley (1999). Their classification includes twelve self-presentation tactics, seven of which refer to the assertive type: ingratiation; enhancement; entitlement; blasting; intimidation; exemplification; supplication; and five defensive tactics: justification; disclaimer; apologies; excuse; selfhandicapping. Our choice was stipulated by the fact that this classification has a set of strategies, containing both defensive and assertive tactics that allow us to make a more detailed range of students' typical behavioral responses.

The experimental part of the study was carried out in stages and was aimed at identifying the level of development of the structural components of social intelligence and the way they are related to the students' self-presentation tactics.

\section{Method}

To measure the subjects' social intelligence and self-presentation tactics we used the scales proposed by D. Lyusin, N. Hall, S. Lee and B. Quigley.

N. Hall's Social Intelligence Scale measures the level of SI structural components by the sum of the following scales:

- Emotional Awareness

- Managing One's Emotions

- Self-Motivation

- Empathy

- Coaching Others' Emotions.

D. Lyusin's Emln Questionnaire is designed to identify the structural components of social intelligence, which is defined as the ability to understand and manage behavior and emotions. The test consists of 46 questions and measures the following areas of SI: interpersonal intelligence (i.e. understanding and managing other's emotions), intrapersonal intelligence (i.e. understanding and managing one's emotions), the ability to understand emotions, the ability to manage emotions. 
S. Lee and B. Quigley's Self-Presentation Tactics Scale was used to identify the subjects' SPT indicators. The participants completed Lee et al.'s (1999) self-presentation tactics scale, a 64-item self-report inventory that measures the frequency with which individuals use 12 self-presentation behaviors. Responses are made on a nine-point scale, from "Very Infrequently" to Very Frequently". The SPT yields scores on defensive and assertive self-presentation dimensions which sum for an index of total self-presentation.

\section{The stages of research}

At the first stage we identified the level of development of the structural components of students' social intelligence, using a questionnaire test Emln proposed by D. Lyusin (2004) and the N. Hall test (2013). According to the survey, the most developed component is emotional awareness, associated with the ability to establish the fact of existence of one's own experience and the experience of others. At the middle level of development there are such components as self-motivation; empathy; recognition of emotions of others. The least developed component was managing behavior and emotions. In order to establish statistical differences in indicators we applied the Mann-Whitney U test. Significant differences were obtained for emotional awareness $(\mathrm{p}=0.05)$; it is higher for the 3 -year students compared to the 1-year students. This is due to the fact that 1 -year students have fewer practice-oriented classes at this stage of education. For the rest of the components of social intelligence no significant differences have been found. The second stage of the experimental work involves the identification of the university students' self-presentation tactics in the educational process. To achieve this goal, we use a self-presentation tactics scale proposed by S. Lee and B. Quigley. Upon the completion of this phase we identified the following: students resorted to ingratiation most frequently due to the choice of their profession, which implies producing a favorable impression, for example, in establishing contacts with others. The rest of the identified tactics is used by the students equally in the context of the situation. The third stage involves evaluating the degree of influence of the components of social intelligence on self-presentation tactics, using the Kruskal-Wallis H test. There are differences in the data measured on 1-year-students' emotional awareness and such selfpresentation tactics as intimidation $(p=0.04)$ and exemplification $(p=0.04)$. These differences are not random and differ in the level of values, i.e., the subjects with high levels of emotional awareness are more likely to use exemplification as their selfpresentation tactic, while the subjects with low levels of this component tend to use intimidation as their self-presentation tactic. This outcome can be explained by the following: the students capable of understanding the causes of their emotions and the consequences of particular emotional states can easily display their behavior as moral, attractive and respectable, even if the situation is not in their favor. The subjects who fail to analyze their own emotions and predict their consequences tend to resort to threats in complicated situations to intimidate the object of self-presentation. In processing the data of 2-year students, we found significant differences between such components of SI as managing behavior and emotions, empathy $(p=0.05)$ and a self-presentation tactic disclaimer $(p=0.03)$. These differences are not random and suggest that the students are not able to control their emotional states. Moreover, the students who have a low level of empathy are likely to resort to the use of such tactic of self-presentation as disclaimer, which involves the subjects' explanation of the reasons for their conduct before an embarrassing situation occurs. Thus, they seem to be trying to prevent any charges against them. While processing the data on the Kruskal-Wallis H test done by III-IV - year students no statistically significant results have been found. The final step of the study was to assess the results using univariate analysis between the components of social intelligence and self-presentation tactics. 


\section{Discussion}

According to the results of the univariate analysis, significant differences have been found between the components of social intelligence and self-presentation tactics: emotional awareness and an assertive self-presentation tactic 7 - intimidation $(\mathrm{p}=0.01)$, managing emotions and assertive self-presentation tactics 9 - entitlement $(\mathrm{p}=0.02)$ and 11 - blasting $(\mathrm{p}=0.03)$. The students with the developed ability to manage their behavior and emotions tend to declare their strengths and past achievements more frequently than other subjects. The subjects with the low and high abilities to control their emotional states are characterized by their negative and critical assessments of other people. These estimates are different by nature, for instance, the students, who are able to manage their emotional states, will criticize other people for the inability to control their emotions, whereas the subjects, who lack this ability, will display intimidation as a response to any situation, which they regard as negative; self-motivation and an assertive self-presentation tactic 12 exemplification $(\mathrm{p}=0.01)$.

The results of the research work are summarized in Table 1.

Table 1. The Impact of the Components of Social Intelligence Self-Presentation Tactics (univariate analysis).

\begin{tabular}{|l|l|l|l|l|l|l|l|l|l|l|l|l|}
\hline \multirow{2}{*}{ EI component } & \multicolumn{10}{|c|}{ Self-presentation tactics } \\
\cline { 2 - 13 } & 1 & 2 & 3 & 4 & 5 & 6 & 7 & 8 & 9 & 10 & 11 & 12 \\
\hline Emotional & $\mathrm{p}=$ & $\mathrm{p}=$ & $\mathrm{p}=$ & $\mathrm{p}=$ & $\mathrm{p}=$ & $\mathrm{p}=$ & $\mathbf{p}=$ & $\mathrm{p}=$ & $\mathrm{p}=$ & $\mathrm{p}=$ & $\mathrm{p}=$ & $\mathrm{p}=$ \\
awareness & 0.5 & 0.4 & 0.3 & 0.1 & 0.1 & 0.5 & $\mathbf{0 . 0 1}$ & 0.3 & 0.5 & 0.4 & 0.3 & 0.2 \\
\hline Managing & $\mathrm{p}=$ & $\mathrm{p}=$ & $\mathrm{p}=$ & $\mathrm{p}=$ & $\mathrm{p}=$ & $\mathrm{p}=$ & $\mathrm{p}=$ & $\mathrm{p}=$ & $\mathbf{p}=$ & $\mathrm{p}=$ & $\mathbf{p}=$ & $\mathrm{p}=$ \\
emotions & 0.2 & 0.1 & 0.3 & 0.1 & 0.5 & 0.9 & 0.07 & 0.5 & $\mathbf{0 . 0 2}$ & 0.1 & $\mathbf{0 . 0 3}$ & 0.9 \\
\hline Self- & $\mathrm{p}=$ & $\mathrm{p}=$ & $\mathrm{p}=$ & $\mathrm{p}=$ & $\mathrm{p}=$ & $\mathrm{p}=$ & $\mathrm{p}=$ & $\mathrm{p}=$ & $\mathrm{p}=$ & $\mathrm{p}=$ & $\mathrm{p}=$ & $\mathbf{p}=$ \\
motivation & 0.9 & 0.9 & 0.8 & 0.9 & 0.4 & 0.2 & 0.21 & 0.6 & 0.9 & 0.9 & 0.5 & $\mathbf{0 . 0 1}$ \\
\hline Empathy & $\mathrm{p}=$ & $\mathrm{p}=$ & $\mathrm{p}=$ & $\mathrm{p}=$ & $\mathrm{p}=$ & $\mathrm{p}=$ & $\mathrm{p}=$ & $\mathrm{p}=$ & $\mathrm{p}=$ & $\mathrm{p}=$ & $\mathrm{p}=$ & $\mathrm{p}=$ \\
& 0.3 & 0.3 & 0.4 & 0.4 & 0.9 & 0.2 & 0.88 & 0.7 & 0.7 & 0.6 & 0.2 & 0.5 \\
\hline Understanding & $\mathbf{p}=$ & $\mathrm{p}=$ & $\mathrm{p}=$ & $\mathrm{p}=$ & $\mathrm{p}=$ & $\mathrm{p}=$ & $\mathrm{p}=$ & $\mathrm{p}=$ & $\mathbf{p}=$ & $\mathbf{p}=$ & $\mathrm{p}=$ & $\mathrm{p}=$ \\
emotions & $\mathbf{0 . 0 4}$ & 0.1 & 0.4 & 0.3 & 0.3 & 0.8 & 0.1 & 0.3 & $\mathbf{0 . 0 4}$ & $\mathbf{0 . 0 3}$ & 0.2 & 0.4 \\
\hline
\end{tabular}

The result suggests that the subjects with a developed ability for self-motivation can display their behavior as more attractive and worthy, even if it is not meaningful to them; perceiving and understanding emotions of other people and assertive self-presentation tactics: 9 - entitlement $(\mathrm{p}=0.04)$ and 10 - enhancement $(\mathrm{p}=0.03)$. The subjects demonstrating the ability to determine and explain emotional states and moods of other subjects including their own, can easily use the information obtained for their own purposes. Thus, for instance, in order to invoke sympathy and approval of the object of selfpresentation, the subjects (at a time when the object of self-presentation is in a good mood) report about their strengths and past achievements, or try to convince him/her that the results of their activities are more positive; perceiving and understanding behavior and emotions of other people and a defensive self-presentation tactic 1 - excuse $(p=0.04)$. The result suggests that the students with high and low levels of this component of SI tend to use excuse as their self-presentation tactic. The reason for the choice of tactics can be different, for example, the subjects with developed ability to recognize other people's emotions determine the emotional state of the object of self-presentation and resort to this tactic, where appropriate, in order to avoid the liability for the committed negative actions. Furthermore, this tactic can serve as the behavior pattern in any negative situation which requires taking responsibility for the actions. Applying univariate analysis to the sample, we have observed the following pattern: the students with high and low levels of development of the structural components of social intelligence tend to use similar selfpresentation tactics (see Supplemental materials). 


\section{Conclusions}

The results of the research provide confirmatory evidence that defensive self-presentation tactics are connected with the low development levels of the component of social intelligence - managing behavior and emotions, while assertive tactics are used by the students with a high level of emotional awareness. To sum up, social intelligence is a complex structure, which requires special development; the structural components of social intelligence influence self-presentation tactics; the analyzed phenomena are interrelated and considered to be professionally important characteristics of students - graduates of "Industrial and civil construction".

\section{References}

1. H.S. Afshar, H. Soodmand R. Masoud, Thinking Skills and Creativity 19, 97-111 (2016)

2. A. Alkozei, S.J. Zachary, W.D.S. Killgore, Journal of Nonverbal Behavior 40, 39-54 (2016)

3. G. Allport, Formation of the person: Collected Works (Smys1, Moscow, 2002)

4. I.N. Andreeva, Psychological Journal 1, 39-43 (2008)

5. R. Bar-On, Psicothema 18, 13-25 (2006)

6. H.E. Gardner, Frames of Mind: The Theory of Multiple Intelligences (Basic book, 1983)

7. D. Golemen, Working with emotional intelligence (AST - Vladimir, Moscow, 2010)

8. G.G. Gorskova, St. Petersburg University Press 1, 25-26 (1999)

9. http://www.trainingcity.ru/interest/articles/model_strukturyi intellekta_dzh._gilforda.h $\underline{\mathrm{tml}}$

10. M. Gutierrez-Moret, R. Ibanez-Martinez, Journal of Education for Teaching 42, 123134 (2016)

11. E.E. Jones, T.S. Pittman, Toward a general theory of strategic self-presentation (Erlbaun, Hillsdale, 1982)

12. D.V. Lyusin, Social Intelligence: Theory, measurement, research (Publ. H. 'Institute of Psychology at the Russian Academy of Sciences', Moscow, 2004)

13. M.A. Manoilova, School Technologies 2, 126-137 (2007)

14. http://psylab.info/Тест_эмоционального_интеллекта_Холла

15. http://psy.1september.ru/article.php?ID=200600905

16. T.V. Semenovskikh, V.V. Duplyankin, Internet-journal "Science of SCIENCE" 5, 12 (2015) DOI: 10.15862/168PVN515

17. T.V. Semenovskikh, V.A. Maslyakova, Scien-tific and Methodological e-magazine 4, 16 (2014)

18. E.A. Sergienko, I.I. Vetrova, The Mayer-Salovey-Caruso Emotional Intelligence Test (Institute of Psychology of the RAS, Moscow, 2010)

19. S. Lee, B. Quigley, 18 training programs: A Guide for Professionals (Rech., St. Petersburg, 2011)

20. J. Zhou, Journal of Employment Counselling 53, 30-47 (2016) 